\title{
A Case of Oral Squamous Cell Carcinoma with Scattered Metastases
}

\author{
Tadanobu Aragaki'1,2, Yasuyuki Michi'2, Shin Nakamura3 ${ }^{3}$, Akira Toriihara ${ }^{4}$, Kou Kayamori ${ }^{3}$, \\ Kiyoshi Harada2 ${ }^{2}$ Tohru Kurabayashi ${ }^{3}$ \\ ${ }^{1}$ Department of Oral and Maxillofacial Surgery, Gunma Prefectural Cancer Center, Gunma, Japan \\ ${ }^{2}$ Section of Maxillofacial Surgery, Tokyo Medical and Dental University, Tokyo, Japan \\ ${ }^{3}$ Section of Oral Radiology, Tokyo Medical and Dental University, Tokyo, Japan \\ ${ }^{4}$ Department of Diagnostic Radiology and Oncology, Tokyo Medical and Dental University, Tokyo, Japan \\ Email: y-mic.mfs@tmd.ac.jp
}

Received 9 August 2014; revised 2 September 2014; accepted 12 September 2014

Copyright (C) 2014 by authors and Scientific Research Publishing Inc.

This work is licensed under the Creative Commons Attribution International License (CC BY).

http://creativecommons.org/licenses/by/4.0/

(c) (7) Open Access

\begin{abstract}
We experienced a case of oral squamous cell carcinoma of the mandible with scattered distant metastases. After neoadjuvant chemoradiotherapy, the patient underwent segmental resection of the right mandible and right radical neck dissection. Surgical specimens confirmed remarkable nodal metastases. Unfortunately, the patient experienced a rapid fatal outcome, and numerous distant metastases were detected on autopsy. Moreover, postoperative 18F-fluorodeoxyglucosepositron emission tomography/computed tomography detected systemic distant metastases in this case. In our opinion, the use of preoperative FDG-PET/CT should be considered for patients with suspected poor prognoses.
\end{abstract}

\section{Keywords}

Oral Cancer, Distant Metastasis, PET/CT, Autopsy, Vascular Invasion

\section{Introduction}

Distant metastases of oral squamous cell carcinoma (OSCC) significantly affect treatment planning and patient survival rates [1]; thus, accurate staging is critical. Imaging with 18F-fluorodeoxyglucose-positron emission tomography/computed tomography (FDG-PET/CT) not only provides information on tissue metabolism, but also has been successfully used to evaluate OSCC [2]-[4]. Without preoperative imaging, tumor staging may sometimes be underestimated. Here, we report a case of OSCC with scattered distant metastases detected by FDGPET/CT 3 weeks after surgery. 


\section{Case Presentation}

A 60-year-old man presented with complaints of dull pain, nerve paralysis, and swelling of the right molar region of the mandible, which had persisted for 3 months. An ulcer-formed depression was found in the right mandibular molar (Figure 1(a), Figure 1(b)). CT revealed severe bone destruction of the mandible beyond the mandibular canal (Figure 1(c), Figure 1(d)) and 1 enlarged cervical lymph node with central necrosis (Figure 1(e)). Although the lungs were also evaluated by CT, no abnormality was found. To evaluate the presence or absence of distant metastases in greater detail, we recommended FDG-PET/CT; however, the patient refused because of the high cost.

A diagnosis of squamous cell carcinoma (SCC) was made by biopsy. The degree of tumor differentiation was poor, and vascular invasion was seen in the connective tissue near the primary tumor (Figure 2(a), Figure 2(b)). After preoperative neoadjuvant radiotherapy ( $\Sigma 40 \mathrm{~Gy} / 20 \mathrm{fr} / 29$ days) and chemotherapy (TS-1 at $100 \mathrm{mg} / \mathrm{day})$ for 2 months, a second CT was performed. No changes were observed with regard to the primary tumor and cervical lymph nodes. Three weeks after the second CT, the patient underwent segmental resection of the right

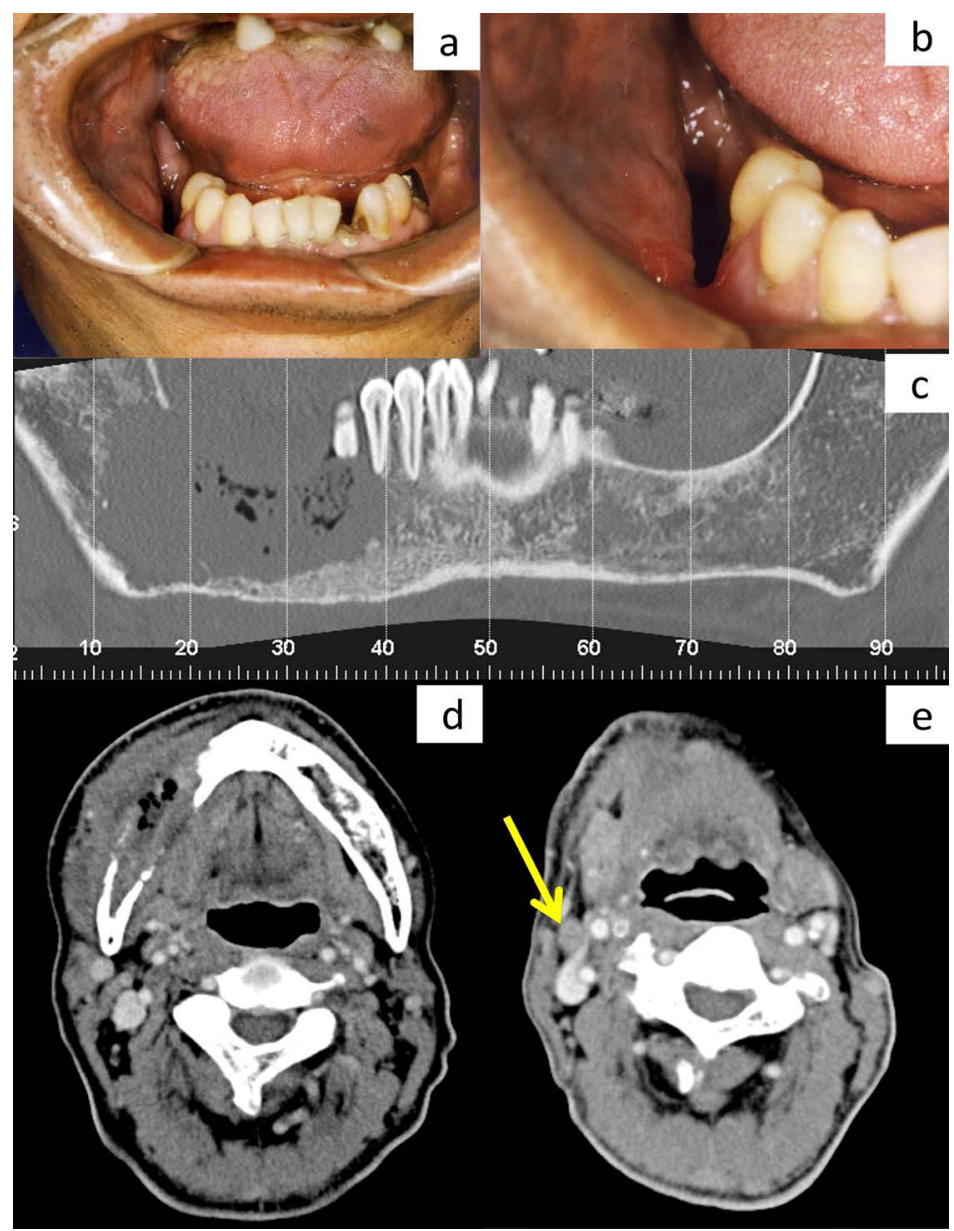

Figure 1. Clinical and computed tomography (CT) findings at initial medical examination. A large soft tissue defect was present in the molor of the right mandible, but a tumor mass was unable to be detectable because tumor grew inwardly (a), (b). On the dental CT image, bone destruction exceeds the mandibular canal and reaches around the inferior margin of the mandible (c). On the axial image of contrast-enhanced CT, the tumor mass, including air space, is observed in the mandible. Marked destruction of the cortical bone is observed around the tumor (d). A swollen lymph node is detected at level 2, with a short diameter of over $10 \mathrm{~mm}(\mathrm{e})$. 


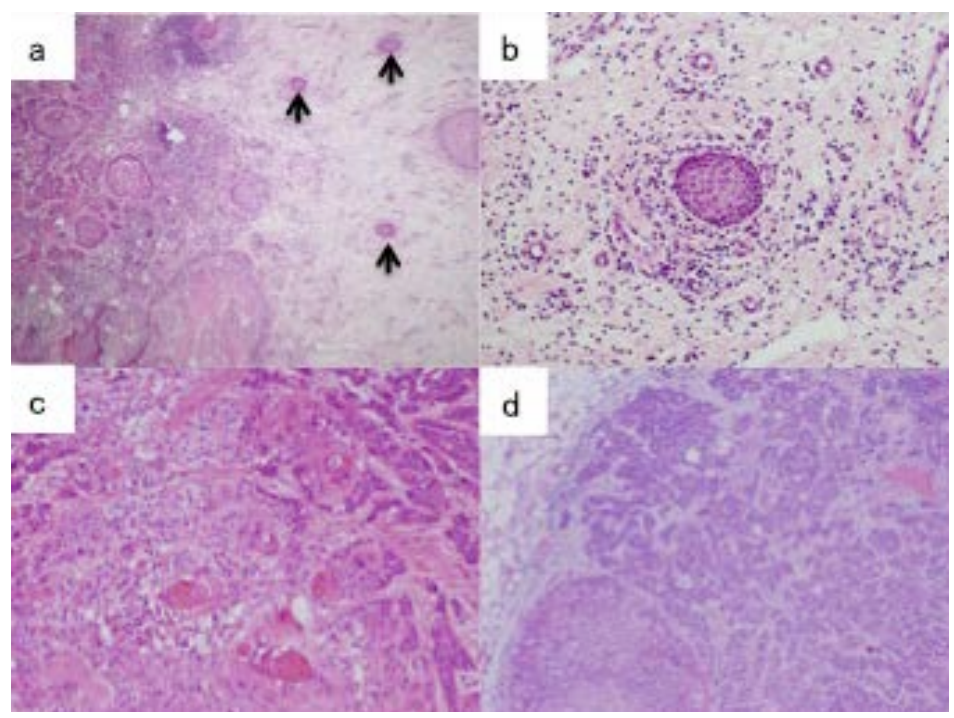

Figure 2. Histopathological findings of the specimens by biopsy and autopsy. Preoperative biopsy of the oral cavity shows scattered tumor cells with poor differentiation (a). The tumor cells invaded the lymph ducts (arrow (a); magnification indicated by arrow (b)). Surgical biopsy shows the aggressive influence of radiological therapy (c). In the cervical lymph node, the tumor cells exhibits capsular spread (d).

mandible and right radical neck dissection.

Because of the effects of additional chemotherapy, we were unable to determine the degree of tumor differentiation by histopathological examination (Figure 2(c)). The resection margin of the primary tumor was free of malignancy. Surprisingly, although preoperative CT detected only 1 positive lymph node, all 71 dissected nodes were histopathologically positive, and approximately $90 \%$ had a diameter $<4 \mathrm{~mm}$. Furthermore, almost half of these metastatic nodes (34/71) showed extracapsular spread (Figure 2(d)). Shortly after surgery, the patient complained of headache and pain in the right shoulder. Thus, 20 days after surgery, FDG-PET/CT was performed, revealing abnormal FDG accumulation in multiple bones and distant organs (Figure 3). On postoperative day 29, he complained of difficulty breathing and subsequently died. An autopsy confirmed peritoneal dissemination and multiple widespread metastases. The autopsy confirmed that the abnormal FDG accumulations in the spleen, thyroid, adrenal gland, and pancreas were indicative of metastases. Distant metastases in the heart, stomach, and liver, which were undetectable by FDG-PET/CT, were also confirmed by autopsy.

\section{Discussion}

Distant metastases occur in $4.2 \%-23.8 \%$ of head and neck SCC cases [5]. The lung is the most common site of distant metastases (66\% of cases), followed by bone (22\%), liver (10\%), skin, mediastinum, and bone marrow. In previous studies, autopsy confirmed distant metastases in 57\% of patients with head and neck SCC [5].

In describing CT criteria, Brekel et al. noted that nodal lymph nodes with a minimal axial diameter of $\geq 11$ $\mathrm{mm}$ in the subdigastric region or $\geq 10 \mathrm{~mm}$ in other lymph node-containing regions were considered metastatic cancer [6] [7]. In this case, although only 1 metastatic lymph node was detected at the level 2 region by preoperative CT, all dissected nodes were confirmed to have metastasis by histopathological examination. While the disease might have progressed rapidly in 3 weeks, we observed no changes in the neck within this period. Concerning the distant metastases, the autopsy showed only small lesions in the lung but multiple large lesions in the heart. Cardiac metastases from OSCC are rare and have seldom been reported in the literature [8]. Thus, the route of tumor spread and pathophysiology of this case may differ from general OSCC.

PET imaging demonstrates physiologic processes [9], while the combination of PET/CT simultaneously depicts both functional and morphologic information [10] [11]. Veit-Haibach et al. reported that combined PET/CT proved to be more accurate in assessing overall TNM-stage than CT and PET + CT [3]. However, few reports have compared the findings of PET/CT with those of autopsy. In this case, the autopsy was performed only 10 


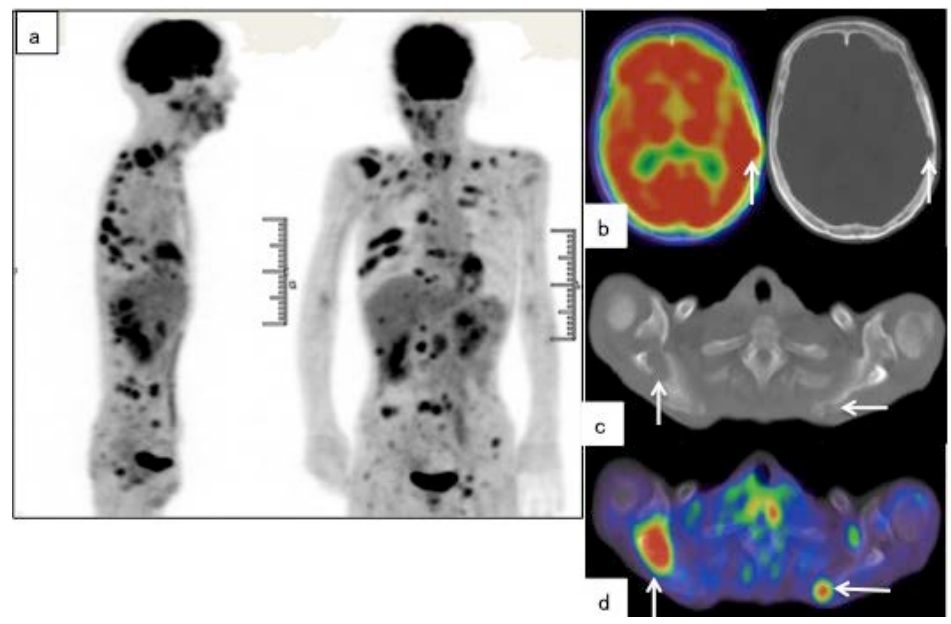

Figure 3. Positron emission tomography/computed tomography (PET/CT) performed 2 weeks after surgery. Scattered metastases are observed in the anterior and coronal PET maximum intensity projection (MIP) images (a). A transverse PET image depicts hot spots at the right skull base and right scapula (arrowhead in (b), (d)), which corresponds to bone absorption on the CT axial image (arrowhead in (c), (e)).

days postmortem; thus, an accurate comparison was possible. We found that the diagnosis made by PET/CT was almost consistent with that made by autopsy. However, the metastases in the heart, liver, and lungs were detected only by autopsy. It is still controversial whether PET/CT should be routinely applied for OSCC treatment planning. Lonneux et al. reported that adding preoperative FDG-PET for conventional staging improved TNM classification and altered the management of $13.7 \%$ of patients [2]. In this case, treatment planning may have changed if preoperative FDG-PET/CT was used. Certain clinical or histopathological findings are known to be important prognostic factors and predictors of lymph node metastasis in neck SCC. Michikawa et al. reported that lymphatic vessel invasion was significantly correlated with lymph node metastasis, and blood vessel invasion was also significantly associated with recurrence and poor prognosis [12]. In this case, prominent vascular invasion was found around the primary tumor. In our opinion, the use of preoperative FDG-PET/CT should be considered for patients with suspected poor prognosis.

However, further investigation of the appropriate application and timing of FDG-PET/CT for OSCC patients is necessary.

\section{References}

[1] Kowalski, L.P., Bagietto, R., Lara, J.R., Santos, R.L., Silva, J.F. and Magrin, J. (2000) Prognostic Significance of the Distribution of Neck Node Metastasis from Oral Carcinoma. Head \& Neck, 22, 207-214. http://dx.doi.org/10.1002/(SICI)1097-0347(200005)22:3<207::AID-HED1>3.0.CO;2-9

[2] Lonneux, M., Hamoir, M., Reychler, H., Maingon, P., Duvillard, C., Calais, G., et al. (2010) Positron Emission Tomography with [18F]Fluorodeoxyglucose Improves Staging and Patient Management in Patients with Head and Neck Squamous Cell Carcinoma: A Multicenter Prospective Study. Journal of Clinical Oncology, 28, 1190-1195. http://dx.doi.org/10.1200/JCO.2009.24.6298

[3] Veit-Haibach, P., Luczak, C., Wanke, I., Fischer, M., Egelhof, T., Beyer, T., et al. (2007) TNM Staging with FDGPET/CT in Patients with Primary Head and Neck Cancer. European Journal of Nuclear Medicine and Molecular Imaging, 34, 1953-1962. http://dx.doi.org/10.1007/s00259-007-0564-5

[4] Goerres, G.W., Schmid, D.T., Grätz, K.W., Von Schulthess, G.K. and Eyrich, G.K. (2003) Impact of Whole Body Positron Emission Tomography on Initial Staging and Therapy in Patients with Squamous Cell Carcinoma of the Oral Cavity. Oral Oncology, 39, 547-551. http://dx.doi.org/10.1016/S1368-8375(03)00016-2

[5] Ferlito, A., Shaha, A.R., Silver, C.E., Rinaldo, A. and Mondin, V. (2001) Incidence and Sites of Distant Metastases from Head and Neck Cancer. ORL, 63, 202-207. http://dx.doi.org/10.1159/000055740

[6] van den Brekel, M.W., Stel, H.V., Castelijns, J.A., Nauta, J.J., van der Waal, I., Valk, J., et al. (1990) Cervical Lymph Node Metastasis: Assessment of Radiologic Criteria. Radiology, 177, 379-384. 
http://dx.doi.org/10.1148/radiology.177.2.2217772

[7] van den Brekel, M.W., Castelijns, J.A. and Snow, G.B. (1994) Detection of Lymph Node Metastases in the Neck: Radiologic Criteria. Radiology, 192, 617-618. http://dx.doi.org/10.1148/radiology.192.3.8058923

[8] Nagata, S., Ota, K., Nagata, M. and Shinohara, M. (2012) Cardiac Metastasis of Head and Neck Squamous Cell Carcinoma. International Journal of Oral and Maxillofacial Surgery, 41, 1458-1462. http://dx.doi.org/10.1016/j.ijom.2012.07.017

[9] Rohren, E.M., Turkington, T.G. and Coleman, R.E. (2004) Radiology Clinical Applications of PET in Oncology. Radiology, 231, 305-332. http://dx.doi.org/10.1148/radiol.2312021185

[10] Bybel, B., Brunken, R.C., Shah, S.N., Wu, G., Turbiner, E. and Neumann, D.R. (2006) PET and PET/CT Imaging: What Clinicians Need to Know. Cleveland Clinic Journal of Medicine, 73, 1075-1087. http://dx.doi.org/10.3949/ccjm.73.12.1075

[11] Schöder, H., Yeung, H.W., Gonen, M., Kraus, D. and Larson, S.M. (2004) Head and Neck Cancer: Clinical Usefulness and Accuracy of PET/CT Image Fusion. Radiology, 231, 65-72. http://dx.doi.org/10.1148/radiol.2311030271

[12] Michikawa, C., Uzawa, N., Kayamori, K., Sonoda, I., Ohyama, Y., Okada, N., et al. (2012) Clinical Significance of Lymphatic and Blood Vessel Invasion in Oral Tongue Squamous Cell Carcinomas. Oral Oncology, 48, 320-324. http://dx.doi.org/10.1016/j.oraloncology.2011.11.014 
Scientific Research Publishing (SCIRP) is one of the largest Open Access journal publishers. It is currently publishing more than 200 open access, online, peer-reviewed journals covering a wide range of academic disciplines. SCIRP serves the worldwide academic communities and contributes to the progress and application of science with its publication.

Other selected journals from SCIRP are listed as below. Submit your manuscript to us via either submit@scirp.org or Online Submission Portal.
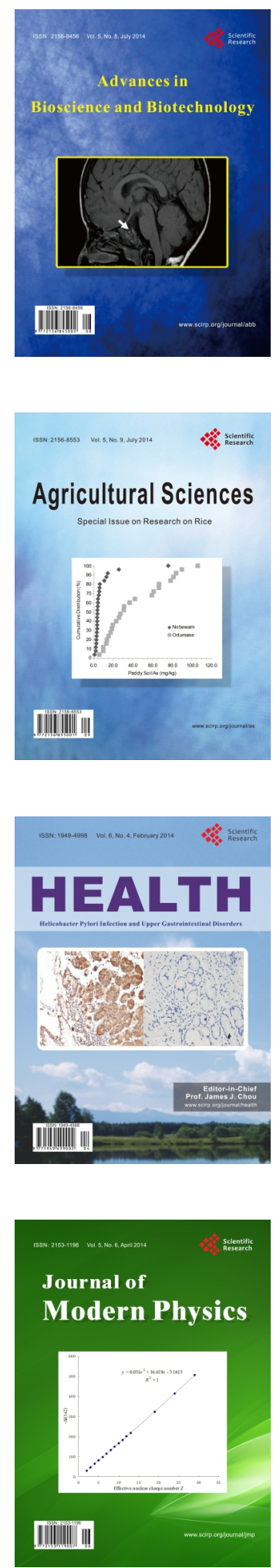
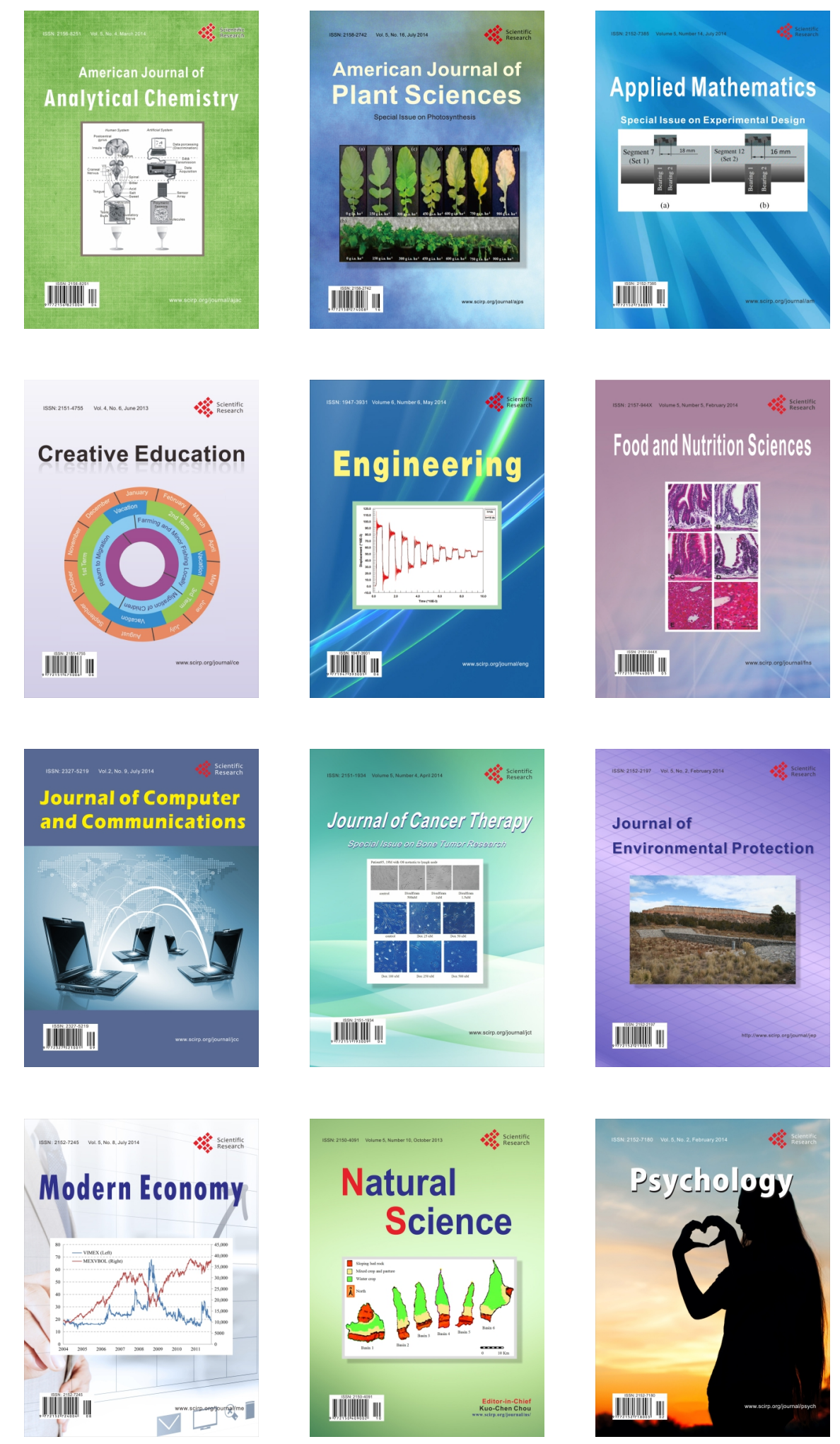